\title{
Mass Spectrometric Characterization of Glycated $\beta$-Lactoglobulin Peptides Derived from Galacto-oligosaccharides Surviving the In Vitro Gastrointestinal Digestion
}

\author{
F. Javier Moreno, ${ }^{a}$ Jesús Eduardo Quintanilla-López, ${ }^{\mathrm{b}, \mathrm{c}}$ \\ Rosa Lebrón-Aguilar, ${ }^{\mathrm{c}}$ Agustín Olano, ${ }^{\mathrm{a}}$ and María Luz Sanz ${ }^{\mathrm{d}}$ \\ ${ }^{a}$ Instituto de Fermentaciones Industriales (CSIC), Madrid, Spain \\ ${ }^{b}$ Departamento de Ingeniería Química Industrial y del Medio Ambiente, ETS Ingenieros Industriales \\ (U.P.M.) Madrid, Spain \\ "Instituto de Química-Física "Rocasolano" (CSIC), Madrid, Spain \\ d Instituto de Química Orgánica General (CSIC), Madrid, Spain
}

A mass spectrometric study has been carried out to elucidate the structures of glycated peptides obtained after in vitro gastrointestinal digestion of bovine $\beta$-lactoglobulin $(\beta-\mathrm{LG})$ glycated with prebiotic galacto-oligosaccharides (GOS). The digests of both native and glycated $\beta$-LG were analyzed by MALDI-MS, LC-ESI-MS, and LC-ESI-MS/MS. MALDI-MS profiles showed marked differences mainly related to the lower intensity of ions corresponding to the digest of glycated $\beta$-LG. Overall, 58 and 23 unglycated peptides covering $97 \%$ and $63 \%$ of the mature $\beta$-LG sequence could be identified in the digests of native and glycated samples, respectively. The LC-ESI-MS analyses corroborated the MALDI-MS results regarding the unglycated peptides but they also enabled an extensive investigation into the digest of glycated $\beta$-LG. Thus, a total of 19 peptides glycated with GOS from two to seven hexose units could be identified. The tandem mass spectra of glycated peptides were mostly characterized by two neutral losses of 1026/1056, 864/894, 702/732, 540/570, 378/408, and 216/246 u, corresponding to the formation of the furylium ion and its subsequent " $\mathrm{CHOH}^{\prime}$ loss, indicative of the peptide glycation with hepta-, hexa-, penta-, tetra-, tri-, and disaccharides, respectively. Also, other minor ionic species containing the furylium ring linked to different galactose units could be also detected, showing the diversity of the fragmentation pattern of peptides glycated with larger size carbohydrates. Finally, the putative GOS glycation sites could be determined at the $\mathrm{NH}_{2}$-terminal Leu residue and at Lys residues located in positions $14,47,75,77,83,91,100,135$, and 138. (J Am Soc Mass Spectrom 2008, 19, 927-937) ( 2008 American Society for Mass Spectrometry

$\mathrm{T}$ The Maillard reaction is one of the most important and complex reactions between reducing sugars and amino acids, peptides, or proteins that may spontaneously occur in living organisms or during food processing. Controversially, either beneficial or detrimental effects have been attributed to the Maillard reaction products (MRP). Thus, some compounds such as reductones and melanoidins have shown antioxidant activity [1,2], whereas the so-called "advanced glycation end products" (AGEs) include a variety of protein adducts implicated in inflammatory reactions and tissue damage $[3,4]$.

The resistance of some MRP to the gastrointestinal digestion environment has been proven [5-7], indicating that they could be available for gut microflora

Address reprint requests to Dr. M. L. Sanz, Instituto de Química Orgánica General (CSIC), Analisis Instrumental y Quimica Ambiental, C/ Juan de la Cierva, 328006 Madrid, Spain. E-mail: mlsanz@iqog.csic.es fermentation. However, little is known about their effects on the growth of these micro-organisms and consequently on chronic gut disorders. Some studies have revealed that the number of anaerobic species increased following fermentation of melanoidins produced from glucose and lysine [8]. Similarly, Dell'Aquila et al. [9] demonstrated that melanoidins derived from gluten glycated with glucose affect the growth of the colonic microbiota. Tuohy et al. [10] showed an increase of the more detrimental microorganisms against a diminution of the beneficial ones (bifidobacteria and lactobacilli) following fermentation of BSA glycated with glucose on fecal bacteria. However, to the best of our knowledge, no gut fermentation studies have so far been performed using proteins glycated with prebiotic carbohydrates (nondigestible compounds, mainly carbohydrates, which selectively stimulate the growth of certain intestinal bacteria beneficially affecting host health [11]). 


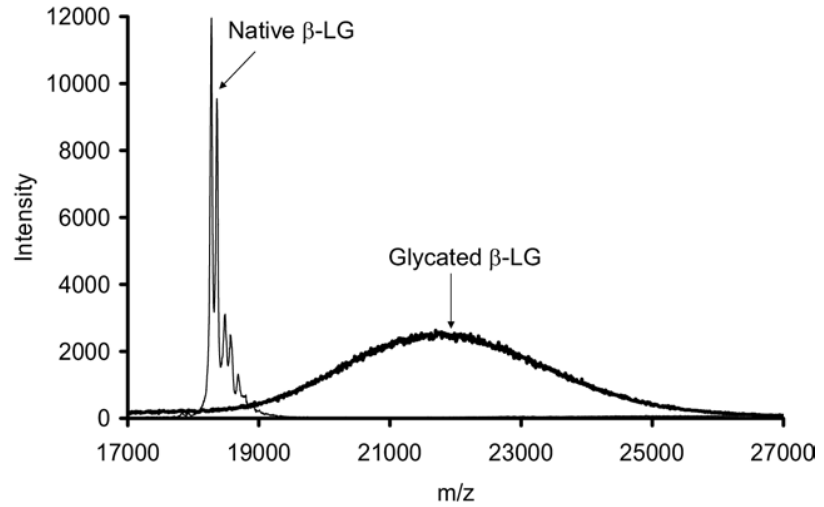

Figure 1. Superimposed MALDI-MS spectra of undigested bovine $\beta$-LG native and glycated with GOS.

Recent researches in the production of prebiotics are leading to the development of persistent compounds, which could achieve the hind gut where most of the intestinal affections take place [12]. Considering that Amadori compounds, the relatively stable products formed during the early stages of the Maillard reaction, can reach the distal regions of the gut [5-7], the conjugation between a prebiotic carbohydrate and a protein could potentially allow carbohydrate to reach the distal parts of the colon and be fermented slowly.

In a recent study, we reported the glycation of bovine $\beta$-lactoglobulin ( $\beta$-LG) with prebiotic carbohydrates, galacto-oligosaccharides (GOS), and its gastrointestinal digestion using a physiologically relevant in vitro model system [13]. The results showed that $\beta$-LG can be efficiently glycated without substantial conformational changes and that the $\beta$-LG-GOS conjugates could form stable glycated peptides surviving the in vitro gastrointestinal digestion. Nevertheless, no further identification of these potentially prebiotic peptides was carried out.

The power of mass spectrometric techniques for the study of glycated and nonglycated peptides has been widely demonstrated $[14,15]$. Matrix-assisted laser desorption ionization (MALDI) and electrospray ionization (ESI) have been used to determine the structure of proteins and peptides and their glycation products with monosaccharides $[14,16,17]$. In the case of $\beta$-LG, several articles describing the identification of lactose and galactose glycation sites using different mass spectrometric strategies have been published in the last decade [18-24]. However, none of these studies addressed the mass spectrometric characterization of the peptide mapping resulting from the action of an in vitro gastrointestinal digestion model which mimics the passage of the $\beta$-LG into the stomach, and then, into the gut. In this work, MS techniques (MALDI-MS, LCESI-MS and LC-ESI-MS/MS) have been used to obtain structural information of the glycated and unglycated peptides derived from the gastric (pepsin) and duodenal (trypsin and chymotrypsin) digestion of $\beta$-LG-GOS conjugates and native $\beta$-LG. The characterization of the glycated peptides is a requirement for understanding their effects on the gut microbiota.

\section{Experimental}

\section{Glycation of $\beta-L G$ with GOS}

Preparation of galacto-oligosaccharides (GOS) and in vitro glycation of $\beta$-LG with GOS was carried out as indicated by Sanz et al. [13]. Briefly, aliquots of a solution consisting of $2.0 \mathrm{mg} / \mathrm{mL} \beta$-LG (mixture of A and B variants) (Sigma, St. Louis, $\mathrm{MO}$ ) and $2.0 \mathrm{mg} / \mathrm{mL}$ GOS in $0.1 \mathrm{M}$ sodium phosphate buffer, pH 7 (Merck, Darmstadt, Germany), were lyophilized. These were kept under vacuum in a desiccator at $40^{\circ} \mathrm{C}$ for 16 days and at water activity of 0.44 , achieved with a saturated $\mathrm{K}_{2} \mathrm{CO}_{3}$ solution (Merck). The original GOS source employed was a commercial product Vivinal-GOS, kindly gifted by Borculo Domo (Hanzeplein, The Netherlands).

\section{In Vitro Gastrointestinal Digestion}

The native and glycated $\beta$-LG were digested in vitro by following the simplified procedure described by Moreno et al. [25]. A $3 \mathrm{mg}$ amount of protein was dissolved in $1 \mathrm{~mL}$ of simulated gastric fluid (SGF; 0.15 $\mathrm{M} \mathrm{NaCl}, \mathrm{pH} 2.5$ ) and the $\mathrm{pH}$ was adjusted to 2.5 with 1 $\mathrm{M} \mathrm{HCl}$. A solution of $0.32 \%$ (wt:vol) porcine pepsin (EC 3.4.23.1) in SGF, pH 2.5 (activity: $3300 \mathrm{U}$ per mg of protein; Sigma), was added at an approximately phys-
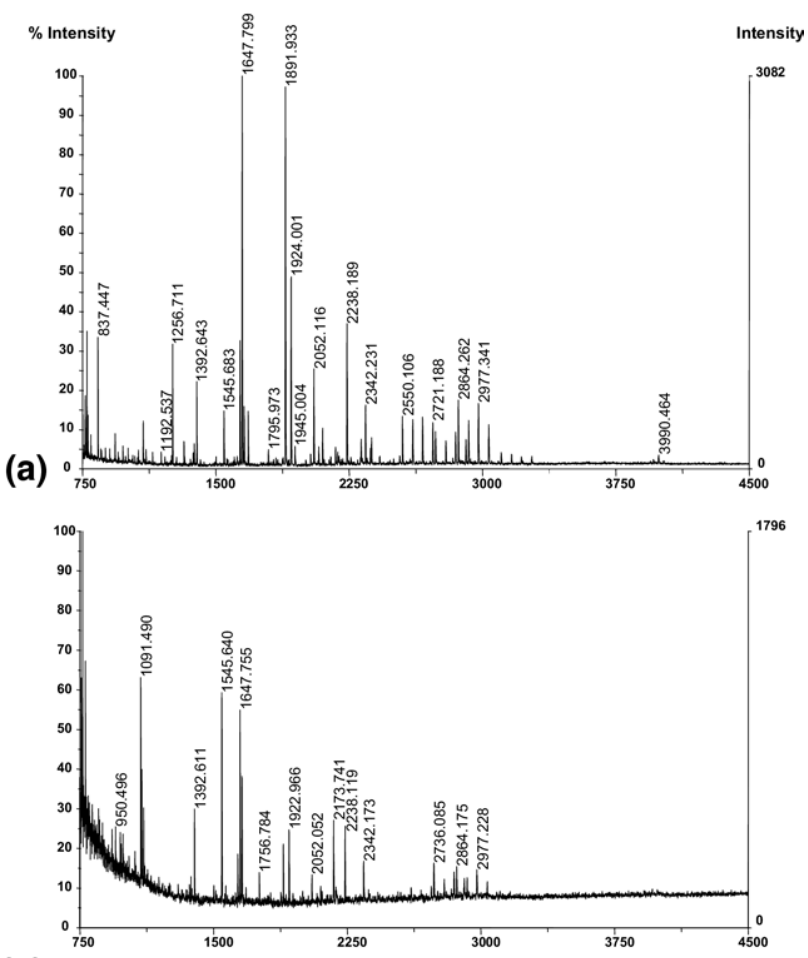

(b) $m / z$

Figure 2. MALDI-MS spectra of in vitro gastrointestinal digests of (a) unglycated $\beta$-LG and (b) glycated $\beta$-LG. 
Table 1. Unglycated peptides identified in native and glycated $\beta$-LG by MALDI-MS

\begin{tabular}{|c|c|c|c|c|c|}
\hline $\begin{array}{l}\text { Putative sequence assigned by using ExPASy } \\
\qquad 02754\end{array}$ & Position & $\begin{array}{c}\text { Exp. Mass } \\
{[\mathrm{M}+\mathrm{H}]^{\mathrm{a}}}\end{array}$ & $\begin{array}{l}\text { Theor. Mass } \\
{[\mathrm{M}+\mathrm{H}]^{\mathrm{a}}}\end{array}$ & $\begin{array}{c}\text { Native } \\
\beta \text {-LG }\end{array}$ & $\begin{array}{c}\text { Glycated } \\
\beta \text {-LG } \\
\end{array}$ \\
\hline $\begin{array}{l}\text { LQKWEND }^{\mathrm{b}} \text { ECAQKK }=\text { LSFNPTQLEEQCHI or } \\
\text { OKWEND }{ }^{\mathrm{b} E C A O K K I}=\text { LSFNPTQLEEQCHI }\end{array}$ & $\begin{array}{l}58-70=149-162^{\mathrm{d}} \text { or } \\
59-71=149-162^{\mathrm{d}}\end{array}$ & 3275.5 & 3275.6 & $x$ & \\
\hline $\begin{array}{l}\text { LOKWENG }{ }^{c} E C A O K K=\text { LSFNPTQLEEQCHI or } \\
\text { OKWENG }{ }^{c} E C A O K K I=\text { LSFNPTQLEEQCHI }\end{array}$ & $\begin{array}{l}58-70=149-162^{\mathrm{d}} \text { or } \\
59-71=149-162^{\mathrm{d}}\end{array}$ & 3217.4 & 3217.6 & $x$ & \\
\hline QKWEND ${ }^{\mathrm{b}}$ ECAOKK $=$ LSFNPTQLEEOCHI & $59-70=149-162^{d}$ & 3162.4 & 3162.5 & $x$ & \\
\hline QKWENG'ECAQKK=LSFNPTQLEEQCHI & $59-70=149-162^{d}$ & 3104.4 & 3104.5 & $\mathrm{X}$ & \\
\hline KWEND ${ }^{\mathrm{b}}$ ECAOKK=LSFNPTQLEEQCHI & $60-70=149-162^{d}$ & 3034.4 & 3034.4 & $\mathrm{X}$ & $\mathrm{X}$ \\
\hline KWENG ${ }^{\mathrm{K}} \mathrm{CAQKK}=$ LSFNPTQLEEQCHI & $60-70=149-162^{d}$ & 2976.3 & 2976.4 & $\mathrm{X}$ & $\mathrm{X}$ \\
\hline WEND ${ }^{\mathrm{b}}$ ECAQKK=LSFNPTQLEEQCHI & $61-70=149-162^{d}$ & 2906.3 & 2906.3 & $\mathrm{X}$ & $x$ \\
\hline WENG'ㄷCAOKK=LSFNPTQLEEOCHI & $61-70=149-162^{d}$ & 2848.2 & 2848.3 & $\mathrm{X}$ & $x$ \\
\hline END $^{\mathrm{b}}$ ECAOKK $=$ LSFNPTOLEEQCHI & $62-70=149-162^{d}$ & 2720.2 & 2720.2 & $x$ & $x$ \\
\hline ENG $^{\mathrm{C} E C A O K K}=$ LSFNPTQLEEOCHI & $62-70=149-162^{d}$ & 2662.2 & 2662.2 & $x$ & \\
\hline NKVLVLDTDYKKYLLFCMENSA & $90-111$ & 2607.1 & 2607.3 & $x$ & $x$ \\
\hline LFCMENSAEPEQSLA'COCLVR & 104-124 (Internal S-S) & 2369.0 & 2369.0 & $x$ & \\
\hline RVYVEELKPTPEGDLEILLQ & $40-59$ & 2341.2 & 2341.3 & $\mathrm{X}$ & $\mathrm{X}$ \\
\hline ENG $^{c} E C A Q K K I I A E K T K I P A V F$ & $62-82$ & 2317.1 & 2317.3 & $X$ & \\
\hline VYVEELKPTPEGDLEILLOK & $41-60$ & 2313.3 & 2313.3 & $\mathrm{X}$ & \\
\hline VEELKPTPEGDLEILLOKW & $43-61$ & 2237.2 & 2237.2 & $X$ & $\mathrm{X}$ \\
\hline YSLAMAASDISLLDAQSAPLR & $20-40$ & 2193.2 & 2193.1 & $X$ & \\
\hline VYVEELKPTPEGDLEILLQ & $41-59$ & 2185.2 & 2185.2 & $x$ & \\
\hline LRVYVEELKPTPEGDLEI or RVYVEELKPTPEGDLEIL & $39-56$ or $40-57$ & 2100.1 & 2100.1 & $X$ & $\mathrm{X}$ \\
\hline VEELKPTPEGDLEILLQK & $43-60$ & 2051.1 & 2051.1 & $\mathrm{X}$ & $\mathrm{X}$ \\
\hline VDDEALEKFDKALKALPM & $128-145$ & 2033.0 & 2033.1 & $\mathrm{x}$ & \\
\hline YLLFCMENSAEPEQSLA ${ }^{c}$ & $102-118$ & 1945.0 & 1944.9 & $X$ & \\
\hline VEELKPTPEGDLEILLQ & $43-59$ & 1923.0 & 1923.0 & $x$ & $x$ \\
\hline VRTPEVDDEALEKFDK & $123-138$ & 1890.9 & 1890.9 & $X$ & $\mathrm{X}$ \\
\hline VEELKPTPEGDLEILL & $43-58$ & 1795.0 & 1795.0 & $x$ & \\
\hline VEELKPTPEGDLEIL & $43-57$ & 1681.9 & 1681.9 & $\mathrm{X}$ & \\
\hline LSFNPTQLEEQCHI & 149-162 & 1658.8 & 1658.8 & $\mathrm{X}$ & $x$ \\
\hline VRTPEVDDEALEKF & $123-136$ & 1647.8 & 1647.8 & $X$ & $x$ \\
\hline TPEVDDEALEKFDK & $125-138$ & 1635.7 & 1635.8 & $x$ & $x$ \\
\hline LSFNPTQLEEOCH & $149-161$ & 1545.7 & 1545.7 & $X$ & $x$ \\
\hline VRTPEVDDEALEK & 123-135 & 1500.7 & 1500.8 & $x$ & $x$ \\
\hline TPEVDDEALEKF & $125-136$ & 1392.6 & 1392.7 & $\mathrm{X}$ & $x$ \\
\hline KWEND ${ }^{\mathrm{b}}$ ECAOKK & $60-70$ & 1378.6 & 1378.6 & $X$ & \\
\hline VRTPEVDDEALE & $123-134$ & 1372.6 & 1372.7 & $\mathrm{X}$ & \\
\hline VLVLDTDYKKY & $92-102$ & 1356.7 & 1356.7 & $X$ & \\
\hline KWENG'ECAQKK & $60-70$ & 1320.6 & 1320.6 & $X$ & \\
\hline KIDALNENKVL & $83-93$ & 1256.7 & 1256.7 & $X$ & \\
\hline WEND ${ }^{\mathrm{b}}$ ECAOKK & $61-70$ & 1250.5 & 1250.5 & $X$ & \\
\hline VEELKPTPEGD & $43-53$ & 1213.6 & 1213.6 & $x$ & \\
\hline WENG'ECAQKK & $61-70$ & 1192.5 & 1192.5 & $X$ & $X$ \\
\hline ENKVLVLDTD & 89-98 & 1145.6 & 1145.6 & $\mathrm{X}$ & \\
\hline LEKFDKALK & 133-141 & 1091.5 & 1091.6 & $x$ & $X$ \\
\hline $\mathrm{END}^{\mathrm{b}} \mathrm{ECAQKK}$ & $62-70$ & 1064.5 & 1064.5 & $x$ & \\
\hline ENG $^{c} E C A O K K$ & $62-70$ & 1006.4 & 1006.5 & $x$ & \\
\hline VTOTMKGLD & $3-11$ & 992.3 & 992.5 & $x$ & $x$ \\
\hline FNPTQLEE & 151-158 & 977.5 & 977.5 & $x$ & \\
\hline ALPMHIRL & 142-149 & 950.5 & 950.6 & $x$ & $x$ \\
\hline LIVTQTMK & $1-8$ & 933.5 & 933.5 & $X$ & \\
\hline TKIPAVFK & $76-83$ & 903.5 & 903.6 & $x$ & \\
\hline LPMHIRL & $143-149$ & 879.5 & 879.5 & $x$ & \\
\hline DAQSAPLR & $33-40$ & 857.4 & 857.4 & $x$ & \\
\hline DKALKALP & 137-144 & 855.0 & 855.5 & $x$ & \\
\hline VLDTDYK & $94-100$ & 853.4 & 853.5 & $x$ & \\
\hline ALPMHIR & $142-148$ & 837.5 & 837.5 & $x$ & \\
\hline GTWYSLA & $17-23$ & 797.4 & 797.4 & $X$ & \\
\hline TKIPAVF & $76-82$ & 775.4 & 775.5 & $X$ & \\
\hline PMHIRL & 144-149 & 766.4 & 766.4 & $\mathrm{X}$ & \\
\hline SLAMAASD or AMAASDIS & $21-28$ or $23-30$ & 765.2 & 765.3 & $x$ & $x$ \\
\hline
\end{tabular}

aMonoisotopic mass values.

${ }^{\mathrm{b}} \beta$-lactoglobulin genetic variant $A$.

${ }^{\mathrm{c}} \beta$-lactoglobulin genetic variant $\mathrm{B}$.

dPeptides containing two fragments linked by disulfide bond (=). 

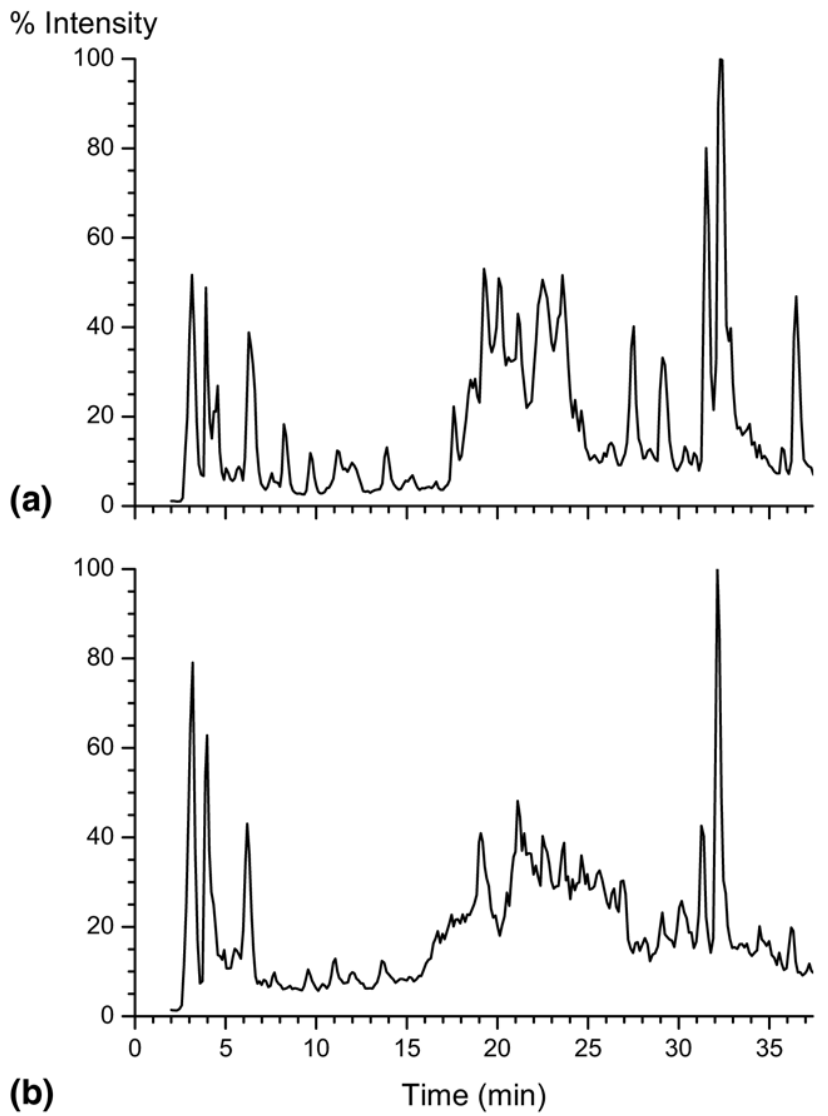

(b)

Time (min)

Figure 3. Total ion current (TIC) chromatograms of in vitro gastrointestinal digests of (a) unglycated $\beta$-LG and (b) glycated $\beta$-LG.

iological ratio of enzyme:substrate (1:20 wt:wt). The digestion was performed at $37^{\circ} \mathrm{C}$ for $2 \mathrm{~h}$.

For the intestinal digestion step, the $\mathrm{pH}$ was raised to 7.5 with $40 \mathrm{mM} \mathrm{NH} \mathrm{CO}_{3}$ (Panreac, Barcelona, Spain) dropwise, and the following was added to adjust the $\mathrm{pH}$ to 6.5 and simulate a duodenal environment: (1) a bile salt mixture containing equimolar quantities $(0.125 \mathrm{M})$ of sodium taurocholate (Sigma) and glycodeoxycholic acid; (Sigma); (2) $1 \mathrm{M} \mathrm{CaCl}_{2}$ (Panreac); (3) $0.25 \mathrm{M}$ bis-tris; $\mathrm{pH} 6.5$ (Sigma). Finally, solutions of porcine trypsin EC 3.4.21.4; $0.05 \%$, wt:vol, type IX-S, activity: $14300 \mathrm{U} / \mathrm{mg}$ of protein; (Sigma), and bovine $\alpha$-chymotrypsin EC 3.4.21.1; $0.1 \%$, wt:vol, type I-S, activity: $62 \mathrm{U} / \mathrm{mg}$ of protein; (Sigma) in water were prepared and added at approximately physiological ratios of $\beta$-LG:trypsin:chymotrypsin $=1:(1 / 400)$ : $(1 / 100)$ (wt:wt). Intestinal digestion of $\beta$-LG was carried out at $37^{\circ} \mathrm{C}$ for $1 \mathrm{~h}$. After protein hydrolysis, digestive enzymes were inactivated by adding a solution of BowmanBirk trypsin-chymotrypsin inhibitor from soybean (Sigma) at a concentration calculated to inhibit twice the amount of trypsin and chymotrypsin present in the digestion mix. Digestions were performed without any derivatization of the sulfhydryl groups of cysteine residues to remain as close as possible to physiological conditions.

\section{MS Analysis}

\section{MALDI-MS}

MALDI-MS measurements were performed on a Voyager DE-PRO mass spectrometer (Applied Biosystems, Foster City, CA) equipped with a pulsed nitrogen laser $(\lambda=337 \mathrm{~nm}, 3 \mathrm{~ns}$ pulse width, and $3 \mathrm{~Hz}$ frequency) and a delayed extraction ion source. Ions generated by laser desorption of both native and glycated $\beta$-LG were introduced into a time of flight analyzer (1.3 m flight path) with an acceleration voltage of $25 \mathrm{kV}, 93 \%$ grid voltage, $0.05 \%$ ion guide wire voltage, and a delay time of $350 \mathrm{~ns}$ in the linear positive ion mode. Mass spectra were obtained over the $\mathrm{m} / \mathrm{z}$ range $10-35 \mathrm{ku}$. Apomyoglobin (Calibration Mixture 3 of Sequazyme Peptide Mass Standards Kit; Applied Biosystems) and carbonic anhydrase (Sigma) were used for external mass calibration. Sinapinic acid (>99\%; Fluka, Buchs, Switzerland) at $10 \mathrm{mg}$ $\mathrm{mL}^{-1}$ in TFA 0.3\%:acetonitrile 70:30 (vol/vol) was used as matrix. Samples were mixed with the matrix at a ratio of $\sim 1: 15$ ( $\mathrm{vol} / \mathrm{vol})$, and $1 \mu \mathrm{L}$ of this solution was spotted onto a flat stainless-steel sample plate and dried in air.

Digestion mixtures of both proteins were analyzed in the same spectrometer but operating in the reflector mode at the following conditions: acceleration voltage, $20 \mathrm{kV}$; grid voltage, $74 \%$; ion guide wire voltage, $0.001 \%$; and delay time, 300 ns. Mass spectra were acquired in the positive ion mode, scanning from $\mathrm{m} / \mathrm{z} 750$ to $\mathrm{m} / \mathrm{z} 4500$. External mass calibration was applied using the monoisotopic $[\mathrm{M}+\mathrm{H}]^{+}$values of des-Arg ${ }^{1}$ bradykinin, angiotensin I, ACTH (1-17 clip), ACTH (18-39 clip), and ACTH (7-38 clip) of the Calibration Mixture 2, Sequazyme Peptide Mass Standards Kit; Applied Biosystems. $\alpha$-Cyano-4-hydroxycinnamic acid (>99\%, Fluka) at $10 \mathrm{mg} \mathrm{mL}^{-1}$ in TFA 0.3\%:acetonitrile 50:50 ( $\mathrm{vol} / \mathrm{vol})$ was used as matrix. Digestion mixtures of native and glycated $\beta$-LG were dilute with water 10 and 5 times, respectively, and mixed with the matrix at a ratio of $1: 4(\mathrm{vol} / \mathrm{vol})$. One $\mu \mathrm{L}$ of this solution was spotted onto a flat stainlesssteel sample plate and dried in air before analysis.

\section{LC-ESI-MS}

LC-MS and LC-MS/MS experiments were carried out on a Finnigan Surveyor pump with quaternary gradient system coupled to a Finnigan LCQ Deca ion trap mass spectrometer using an ESI interface. Sample injections $(5 \mu \mathrm{L})$ were carried out by a Finnigan Surveyor autosampler. All instruments from Thermo Fisher Scientific (San Jose, CA), formic acid of analytical grade (Merck, Darmstadt, Germany), and Milli-Q water obtained using a Millipore, Bedford, MA system were used.

The digestion mixtures of both glycated and unglycated $\beta$-LG were diluted 1:2 with water, and their separation performed at $25^{\circ} \mathrm{C}$ on a Hypersil HyPurity 
Table 2. Unglycated peptides identified in the digests of native and glycated $\beta$-LG by LC-ESI-MS

\begin{tabular}{|c|c|c|c|c|c|c|c|}
\hline $\mathrm{RT}$ (min) & $\begin{array}{l}\text { Putative sequence assigned } \\
\text { by using ExPASy P02754 }\end{array}$ & Position & $\begin{array}{l}\text { Exp. mass } \\
{[\mathrm{M}+\mathrm{H}]^{\mathrm{a}}}\end{array}$ & $\begin{array}{c}\text { Theor. mass } \\
{[\mathrm{M}+\mathrm{H}]^{\mathrm{a}}}\end{array}$ & $\begin{array}{c}\text { Main } \\
\text { charge } \\
\text { state }\end{array}$ & $\begin{array}{l}\text { Native } \\
\beta \text {-LG }\end{array}$ & $\begin{array}{c}\text { Glycated } \\
\beta \text {-LG }\end{array}$ \\
\hline 3.9 & IIAEK & $71-75$ & 573.3 & 573.4 & +1 & $X$ & $X$ \\
\hline 3.9 & KIDALNENK & $83-91$ & 1044.6 & 1044.6 & +1 & $X$ & \\
\hline 4.2 & VLDTDYK & $94-100$ & 853.4 & 853.5 & +1 & $X$ & $X$ \\
\hline 4.6 & KIDALN & $83-88$ & 673.3 & 673.4 & +1 & $X$ & $X$ \\
\hline 5.0 & KIDALNE & $83-89$ & 802.4 & 802.4 & +1 & $X$ & $X$ \\
\hline 5.8 & KALPM & $141-145$ & 559.2 & 559.3 & +1 & $X$ & $X$ \\
\hline 6.3 & KIIAEK & $70-75$ & 701.2 & 701.5 & +1 & $X$ & $X$ \\
\hline 7.6 & LKPTPEGDL & $46-54$ & 969.4 & 969.5 & +2 & $\mathrm{X}$ & $\mathrm{X}$ \\
\hline 8.2 & LIVTQTMK & $1-8$ & 933.5 & 933.5 & +2 & $X$ & \\
\hline 11.2 & VLVLDTDYK & $92-100$ & 1065.4 & 1065.6 & +2 & $X$ & $X$ \\
\hline 12.2 & TPEVDDEALE & $125-134$ & 1117.4 & 1117.5 & +1 & $\mathrm{X}$ & $\mathrm{X}$ \\
\hline 12.9 & VEELKPTPEGDLE & $43-55$ & 1455.6 & 1455.7 & +2 & $X$ & \\
\hline 14.9 & VRTPEVDDEALE & $123-134$ & 1372.6 & 1372.7 & +2 & $\mathrm{X}$ & $\mathrm{X}$ \\
\hline 16.0 & ALPMHIR & $142-148$ & 837.5 & 837.5 & +1 & $X$ & \\
\hline 16.6 & VEELKPTPEGDL & $43-54$ & 1326.6 & 1326.7 & +2 & $X$ & $X$ \\
\hline 17.0 & EALEKF & $131-136$ & 736.3 & 736.4 & +1 & $X$ & \\
\hline 17.2 & WENG'ECAQKK & $61-70$ & 1192.4 & 1192.5 & +1 & $X$ & $X$ \\
\hline 17.6 & LIVTQTM & $1-7$ & 805.3 & 805.4 & +1 & $X$ & $X$ \\
\hline 18.8 & KIDALNENKVL & $83-93$ & 1256.7 & 1256.7 & +2 & $X$ & $\mathrm{X}$ \\
\hline 19.3 & VAGTWY & $15-20$ & 696.2 & 696.3 & +1 & $X$ & $X$ \\
\hline 20.2 & TPEVDDEALEKFDK & $125-138$ & 1635.7 & 1635.8 & +2 & $\mathrm{X}$ & $\mathrm{X}$ \\
\hline 20.6 & VRTPEVDDEALEKFDK & $123-138$ & 1890.9 & 1890.9 & +2 & $X$ & $\mathrm{X}$ \\
\hline 21.1 & SFNPTQL & $150-156$ & 806.3 & 806.4 & +1 & $X$ & $X$ \\
\hline 22.0 & TKIPAVF & $76-82$ & 775.4 & 775.5 & +1 & $X$ & $\mathrm{X}$ \\
\hline 22.5 & VRTPEVDDEALEKF & $123-136$ & 1647.8 & 1647.8 & +2 & $\mathrm{X}$ & $X$ \\
\hline 22.6 & TPEVDDEALEKF & $125-136$ & 1392.6 & 1392.7 & +2 & $\mathrm{X}$ & $\mathrm{X}$ \\
\hline 23.6 & IPAVF & $78-82$ & 546.3 & 546.3 & +1 & $X$ & $X$ \\
\hline 24.2 & VLVLDTDY & $92-99$ & 937.4 & 937.5 & +1 & $\mathrm{X}$ & \\
\hline 25.6 & LFCMENSAEPEQSLA'CQCLVR & 104-124 (internal S-S) & 2369.0 & 2369.0 & +3 & $X$ & \\
\hline 26.3 & VAGTWYS or CMENSAE & 15-21 or $106-112$ & 783.1 & 783.4 or 783.3 & +1 & $\mathrm{X}$ & \\
\hline 26.9 & KWENG'ECAQKK & $60-70$ & 1320.4 & 1320.6 & +1 & $\mathrm{X}$ & \\
\hline 27.3 & MAASDISLL & 24-32 & 920.3 & 920.5 & +1 & $\mathrm{X}$ & \\
\hline 27.5 & VEELKPTPEGDLEIL & $43-57$ & 1681.9 & 1681.9 & +2 & $\mathrm{X}$ & $X$ \\
\hline 27.9 & AMAASDISLL & $23-32$ & 991.4 & 991.5 & +1 & $X$ & $\mathrm{X}$ \\
\hline 29.4 & VEELKPTPEGDLEILLOK & $43-60$ & 2050.9 & 2051.1 & +3 & $X$ & $X$ \\
\hline 29.4 & VYVEELKPTPEGDLEIL & $41-57$ & 1943.7 & 1944.0 & +2 & $X$ & $\mathrm{X}$ \\
\hline 30.4 & VYVEELKPTPEGDLEILLQK & $41-60$ & 2313.3 & 2313.3 & +3 & $\mathrm{X}$ & \\
\hline 30.8 & RVYVEELKPTPEGDLEILLQ & $40-59$ & 2341.2 & 2341.3 & +3 & $X$ & \\
\hline 31.5 & VEELKPTPEGDLEILLQ & $43-59$ & 1923.0 & 1923.0 & +2 & $\mathrm{X}$ & $X$ \\
\hline 32.2 & SLAMAASDISLL & $21-32$ & 1191.5 & 1191.6 & +1 & $\mathrm{X}$ & $\mathrm{X}$ \\
\hline 32.5 & YLLF & $102-105$ & 555.2 & 555.3 & +1 & $\mathrm{X}$ & $\mathrm{X}$ \\
\hline 32.9 & VYVEELKPTPEGDLEILLQ & $41-59$ & 2185.0 & 2185.2 & +2 & $\mathrm{X}$ & $X$ \\
\hline 34.0 & KGLDIQKVAGTW & $8-19$ & 1316.1 & 1315.7 & +1 & $\mathrm{X}$ & $\mathrm{X}$ \\
\hline 35.6 & YSLAMAASDISLL & $20-32$ & 1354.5 & 1354.7 & +1 & $X$ & $X$ \\
\hline 36.5 & VDDEALEKFDKALKALPM & $128-145$ & 2033.0 & 2033.1 & +2 & $\mathrm{X}$ & \\
\hline 36.6 & VEELKPTPEGDLEILLQKW & 43-61 & 2237.2 & 2237.2 & +3 & $\mathrm{X}$ & $X$ \\
\hline 37.2 & WEND ${ }^{\mathrm{b}}$ ECAQKK & $61-70$ & 1250.7 & 1250.5 & +1 & $\mathrm{X}$ & \\
\hline
\end{tabular}

aMonoisotopic mass values.

${ }^{\mathrm{b}} \beta$-Lactoglobulin genetic variant $A$.

${ }^{c} \beta$-Lactoglobulin genetic variant $\mathrm{B}$.

C18 $(100 \mathrm{~mm} \times 2.1 \mathrm{~mm}, 3 \mu \mathrm{m})$ column (Thermo Fisher Scientific) at a flow rate of $100 \mu \mathrm{L} \mathrm{min}{ }^{-1}$. A gradient of two eluents was used: eluent $\mathrm{A}$ consisted in $0.1 \%$ (vol/vol) of formic acid (analytical grade; Merck, Darmstadt, Germany) in water, and eluent B in acetonitrile (LC-MS Chromasolv grade; Riedel-de Haën, Seelz, Germany) containing $0.1 \%$ of formic acid (vol/vol). The elution program was applied as follows: at the start $5 \%$ $\mathrm{B}$; after $5 \mathrm{~min}$ the percentage of B was linearly increased to $50 \%$ in $50 \mathrm{~min} ; 50 \%$ to $90 \%$ B linear from 55 to $57 \mathrm{~min}$; $90 \%$ B isocratic from 57 to $70 \mathrm{~min}$; ramped to original composition in $1 \mathrm{~min}$, then equilibrated for $15 \mathrm{~min}$.

The mass spectrometer spray voltage was set at 4.5 $\mathrm{kV}$, heated capillary temperature at $200{ }^{\circ} \mathrm{C}$, nitrogen (99.5\% purity) was used as sheath $\left(0.6 \mathrm{~L} \mathrm{~min}^{-1}\right)$ and auxiliary (6 $\mathrm{L} \mathrm{min}^{-1}$ ) gas, and helium $(99.999 \%$ purity) as the collision gas. Mass spectra were recorded in the positive ion mode. MS/MS data were acquired in the 


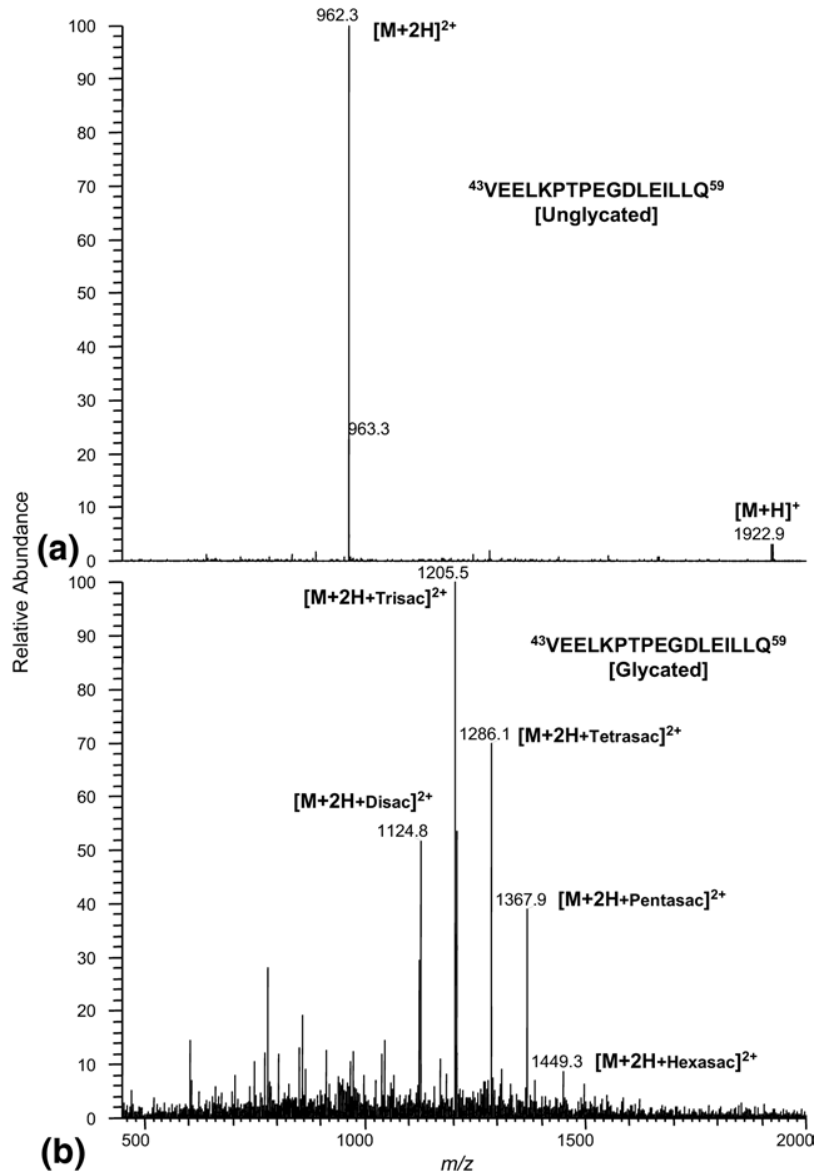

Figure 4. ESI mass spectra of doubly charged ions corresponding to (a) unglycated and (b) glycated ${ }^{43} \mathrm{~V}-\mathrm{Q}^{59}$ peptide.

automatic data-dependent mode with relative collision energy of $35 \%$.

\section{Data Treatment}

MALDI-MS data were evaluated by the Data Explorer program (Voyager 5.1 Software with Data Explorer; Applied Biosystems). The LC-MS system, data acquisition and processing were managed by Xcalibur software, (1.2 version; Thermo Fisher Scientific).

The assignment of observed ions to the corresponding amino acid sequences was based on the known sequence of $\beta$-LG [26] by using the protein database Swiss-Prot and TrEMBL and the tools Peptide Mass and FindPept available at www.expasy.org. Parameters for the search were the following: (1) Monoisotopic peptide masses were indicated as $[\mathrm{M}+\mathrm{H}]^{+}$with cysteines treated with nothing; (2) as enzymes, pepsin, and trypsin/chymotrypsin were chosen; (3) four missed cleavages were allowed; (4) peptides with a mass larger than $500 \mathrm{u}$ were displayed; (5) the mass tolerance was kept at $0.5 \mathrm{u}$.

All full scan MS/MS spectral data were searched using the Bioworks version 3.1 suite of programs (Thermo Fisher Scientific). A precursor mass tolerance of $1.4 \mathrm{u}$ was used to search the resulting DTA files against computer-predicted fragments. All Bioworks 3.1 output files were further filtered according to crosscorrelation (Xcorr) scores as a function of charge states to increase confidence limits. Specifically, the Xcorr cutoff values used to determine acceptable peptide matches were 1.5 for digest fragments originating from precursor ions with a charge state of one, 2.0 for digest fragments originating from doubly charged precursor ions, and 2.5 for triply charged ions.

\section{Results and Discussion}

\section{Determination of the Extent of Glycation}

The MALDI-MS analysis of undigested $\beta$-LG stored with GOS for 16 days demonstrated that this protein can be glycated through the Maillard reaction to a considerable and variable degree (Figure 1). Either the presence of two $\beta$-LG genetic variants with multiple glycation sites $\left(15 \mathrm{Lys}, 3 \mathrm{Arg}\right.$, and the $\mathrm{NH}_{2}$-terminal Leu residues) or the use of GOS with different degrees of polymerization (from 2 to 7 ) explain the great variety of individual glycated protein species obtained after storage. Thus, the mass spectrum of the native $\beta$-LG was

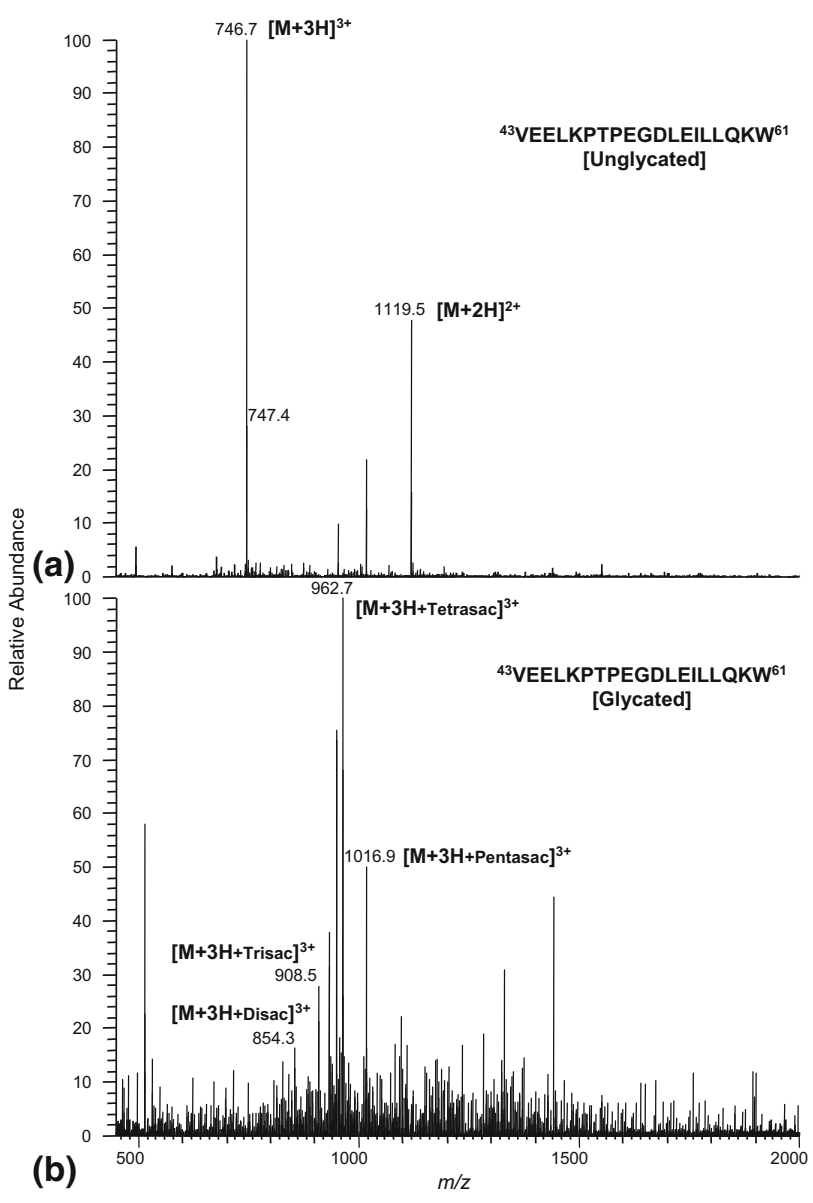

Figure 5. ESI mass spectra of triply charged ions corresponding to (a) unglycated and (b) glycated ${ }^{43} \mathrm{~V}-\mathrm{W}^{61}$ peptide. 
Table 3. Glycated peptides of $\beta$-LG identified by LC-ESI-MS and LC-ESI-MS/MS. The glycated amino acid is indicated by an asterisk.

\begin{tabular}{|c|c|c|c|c|c|c|}
\hline $\mathrm{RT}(\min )$ & $\begin{array}{l}\text { Putative sequence assigned } \\
\text { by using ExPASy P02754 }\end{array}$ & Position & $\begin{array}{l}\text { Exp. mass } \\
{[\mathrm{M}+\mathrm{H}]^{\mathrm{a}}}\end{array}$ & $\begin{array}{l}\text { Theor. mass } \\
\qquad[\mathrm{M}+\mathrm{H}]^{\mathrm{a}}\end{array}$ & $\begin{array}{l}\text { Main charge } \\
\text { state }\end{array}$ & D.P. GOS \\
\hline \multirow[t]{2}{*}{$4.0-4.1$} & \multirow[t]{2}{*}{ IIAEK* } & \multirow[t]{2}{*}{$71-75$} & 1059.6 & 1059.4 & \multirow[t]{2}{*}{+1} & 3 \\
\hline & & & 1221.5 & 1221.4 & & 4 \\
\hline 4.1 & ENK*VLVLDTD & $89-98$ & 1955.5 & 1955.6 & +2 & 5 \\
\hline 4.2 & K*IDALNE & $83-89$ & 1450.4 & 1450.4 & +1 & 4 \\
\hline \multirow[t]{2}{*}{$4.5-4.6$} & \multirow[t]{2}{*}{ FDK*ALK } & \multirow[t]{2}{*}{$136-141$} & 1207.5 & 1207.4 & \multirow[t]{2}{*}{+2} & 3 \\
\hline & & & 1369.8 & 1369.4 & & 4 \\
\hline \multirow[t]{4}{*}{$8.2-9.2$} & \multirow[t]{4}{*}{ LK*PTPEGDL } & \multirow[t]{4}{*}{$46-54$} & 1293.9 & 1293.5 & \multirow[t]{4}{*}{+2} & 2 \\
\hline & & & 1455.9 & 1455.5 & & 3 \\
\hline & & & 1617.9 & 1617.5 & & 4 \\
\hline & & & 1779.7 & 1779.5 & & 5 \\
\hline \multirow[t]{5}{*}{$12.7-13.3$} & \multirow[t]{5}{*}{ TK*IPAVFK } & \multirow[t]{5}{*}{$76-83$} & 1389.4 & 1389.6 & \multirow[t]{5}{*}{+1} & 3 \\
\hline & & & 1551.5 & 1551.6 & & 4 \\
\hline & & & 1713.9 & 1713.6 & & 5 \\
\hline & & & 1875.5 & 1875.6 & & 6 \\
\hline & & & 2037.9 & 2037.6 & & 7 \\
\hline $14.4-16.2$ & VEELK*PTPEGDL & $43-54$ & 1650.5 & 1650.7 & +2 & 2 \\
\hline & & & 1813.1 & 1812.7 & & 3 \\
\hline & & & 1974.7 & 1974.7 & & 4 \\
\hline & & & 2136.9 & 2136.7 & & 5 \\
\hline 15.4 & L*IVTQTM & $1-7$ & 1129.3 & 1129.4 & +1 & 2 \\
\hline $17.0-18.0$ & $\mathrm{~K}^{*}$ IDALNENK*VL & $83-93$ & 1581.4 & 1580.7 & +2 & 2 \\
\hline & & & 1743.4 & 1742.7 & & 3 \\
\hline & & & 1905.2 & 1904.7 & & 4 \\
\hline & & & 2067.4 & 2066.7 & & 5 \\
\hline & & & 2229.4 & 2228.7 & & 6 \\
\hline 19.0-20.0 & VLVLDTDYK*K & $92-101$ & 1841.5 & 1841.7 & +2 & 4 \\
\hline & & & 2003.5 & 2003.7 & & 5 \\
\hline & & & 2165.5 & 2165.7 & & 6 \\
\hline $20.7-21.5$ & TK*IPAVF & $76-82$ & 1261.5 & 1261.5 & +2 & 3 \\
\hline & & & 1423.8 & 1423.5 & & 4 \\
\hline & & & 1585.9 & 1585.5 & & 5 \\
\hline $20.6-21.4$ & TPEVDDEALEK ${ }^{*} \mathrm{~F}$ & $125-136$ & 1879.0 & 1878.7 & +2 & 3 \\
\hline & & & 2041.4 & 2040.7 & & 4 \\
\hline & & & 2203.0 & 2202.7 & & 5 \\
\hline $25.1-25.9$ & VEELK*PTPEGDLEIL & $43-57$ & 2168.0 & 2167.9 & +2 & 3 \\
\hline & & & 2330.0 & 2329.9 & & 4 \\
\hline & & & 2492.0 & 2491.9 & & 5 \\
\hline & & & 2654.0 & 2653.9 & & 6 \\
\hline 25.3 & VRTPEVDDEALEK ${ }^{*}$ FDK ${ }^{*} \mathrm{AL}$ & $123-140$ & 2723.4 & 2723.1 & +3 & 4 \\
\hline $25.1-26.0$ & TPEVDDEALEK*FDK*AL & $125-140$ & 2306.9 & 2305.9 & +3 & 3 \\
\hline & & & 2468.4 & 2467.9 & & 4 \\
\hline & & & 2630.4 & 2629.9 & & 5 \\
\hline $25.0-26.6$ & GLDIQK*VAGTWY & $9-20$ & 1836.8 & 1836.7 & +2 & 3 \\
\hline & & & 1998.8 & 1998.7 & & 4 \\
\hline & & & 2160.5 & 2160.7 & & 5 \\
\hline & & & 2323.0 & 2322.7 & & 6 \\
\hline $28.0-28.9$ & VEELK*PTPEGDLEILLQK & $43-60$ & 2375.6 & 2375.1 & +3 & 2 \\
\hline & & & 2537.5 & 2537.1 & & 3 \\
\hline & & & 2699.3 & 2699.1 & & 4 \\
\hline & & & 2861.4 & 2861.1 & & 5 \\
\hline $30.0-30.9$ & VEELK*PTPEGDLEILLQ & $43-59$ & 2247.0 & 2247.0 & +2 & 2 \\
\hline & & & 2410.0 & 2409.0 & & 3 \\
\hline & & & 2571.2 & 2571.0 & & 4 \\
\hline & & & 2732.8 & 2733.0 & & 5 \\
\hline & & & 2895.6 & 2895.0 & & 6 \\
\hline $34.9-35.9$ & VEELK*PTPEGDLEILLQK*W & $43-61$ & 2561.5 & 2561.2 & +3 & 2 \\
\hline & & & 2723.5 & 2723.2 & & 3 \\
\hline & & & 2885.6 & 2885.2 & & 4 \\
\hline & & & 3047.2 & 3047.2 & & 5 \\
\hline
\end{tabular}

aMonoisotopic mass values. 

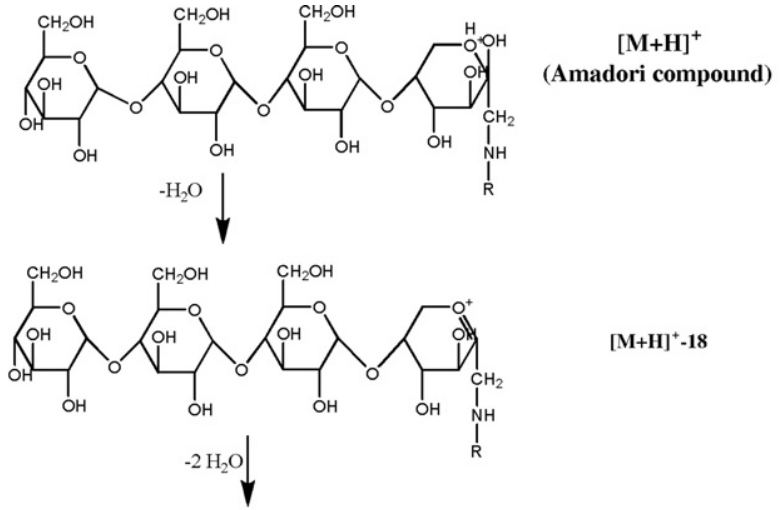

$[\mathrm{M}+\mathrm{H}]^{+}-18$

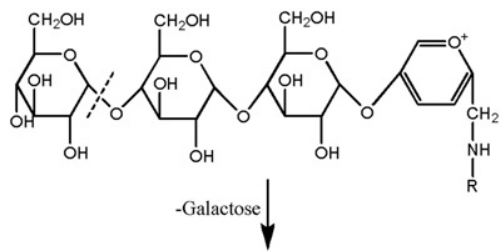

$[\mathrm{M}+\mathrm{H}]^{+}-54$

$[\mathrm{M}+\mathrm{H}]^{+}-216$
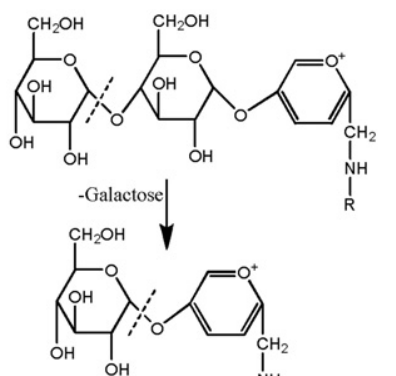

$\mathrm{CH}_{2}$

$[\mathrm{M}+\mathrm{H}]^{+}-378$

$[\mathrm{M}+\mathrm{H}]^{+}-\mathbf{5 4 0}$ (Furylium ion) -Galactose<smiles>[2H]N</smiles>

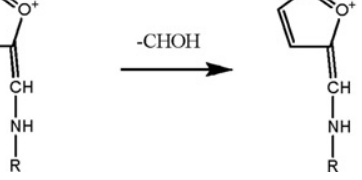<smiles>NCC=C1C=CC(CO)C1</smiles>

$-\mathrm{CHOH}$

Scheme 1. Proposed dissociation pathway for peptides glycated with galacto-oligosaccharides of degree of polymerization $>2$ following ESI-MS/MS analysis.

characterized by the molecular mass values of 18,278 and $18,363 \mathrm{u}$ corresponding to the theoretical masses of the variants $\mathrm{B}$ and $\mathrm{A}$, respectively. Other minor masses attributed mainly to some matrix-adducts were also detected in the native $\beta$-LG mass spectrum (Figure 1). However, a Gaussian distribution of masses over the range of approximately $\mathrm{m} / \mathrm{z} 19,000$ to $25,000 \mathrm{u}$ was detected for the glycated $\beta$-LG. The Gaussian peak showed a maximum of intensity at $\sim 21,700 \mathrm{u}$, indicating an increase of $\sim 19 \%$ in the molecular mass of the $\beta$-LG sequence (Figure 1).

\section{Identification of $\beta$-LG Peptides Resulting from the In Vitro Gastrointestinal Digestion}

Both native and glycated $\beta$-LG were subjected to a pepsin digestion; then they were hydrolyzed by trypsin and chymotrypsin simulating a duodenal environment. As expected, both proteins were very resistant to pepsinolysis (data not shown) because $\beta$-LG is a poor substrate for pepsin [27-30]. Nevertheless, the duodenal digestion (trypsin and chymotrypsin) of the native and glycated $\beta$-LG gave rise to a very complex mixture of peptides after $1 \mathrm{~h}$ of incubation as was previously observed by reversed-phase LC-UV [13]. The difference in amino acid specificity of these two enzymes may contribute to the release of a great number of peptides. Trypsin cleaves on the C-side of basic residues (Arg and Lys) whilst chymotrypsin requires an aromatic or bulky nonpolar side-chain (Phe, Tyr, Trp, Leu, Met) on the
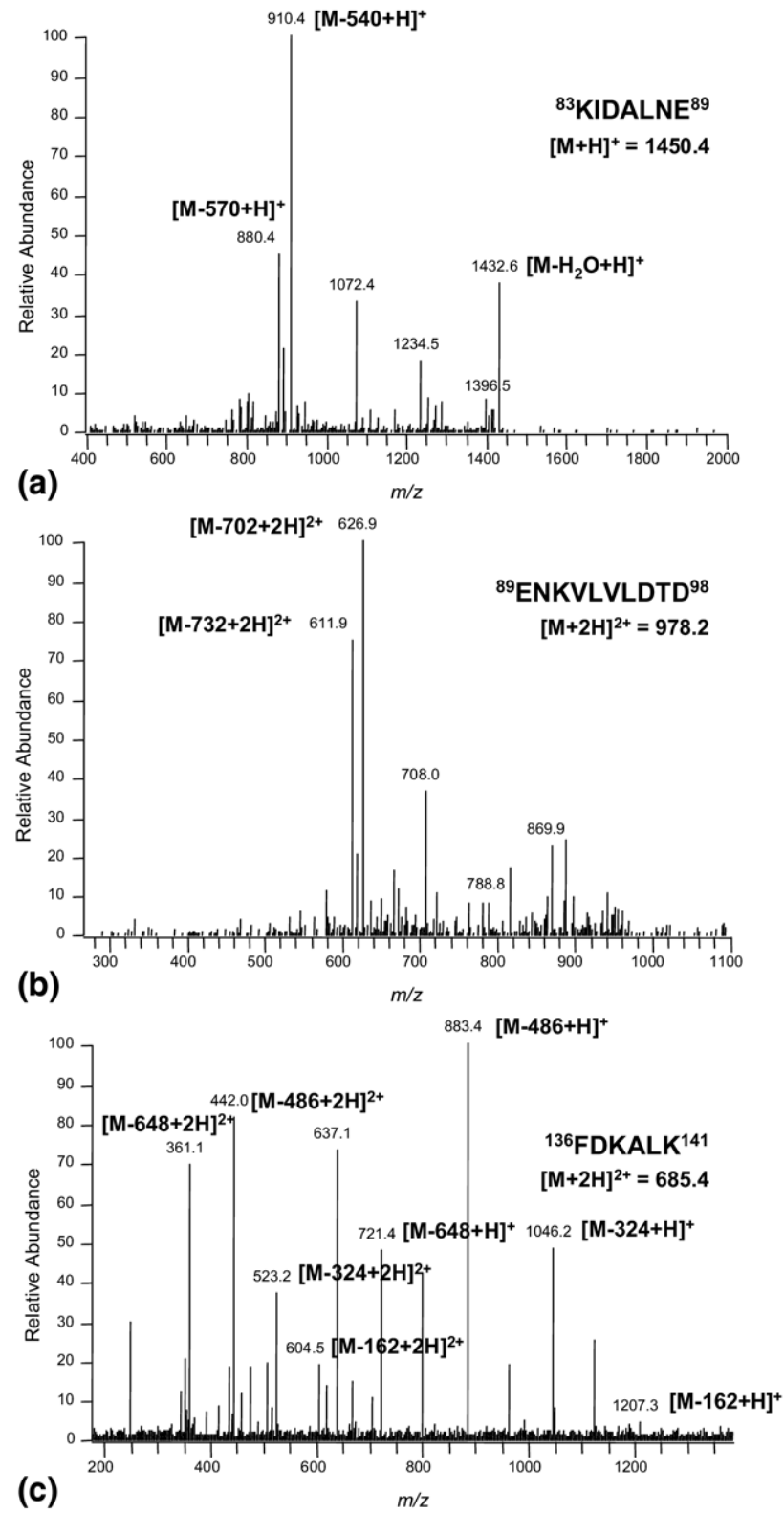

Figure 6. MS/MS spectra of single charged ion corresponding to (a) glycated ${ }^{83} \mathrm{~K}-\mathrm{E}^{89}$ peptide, and doubly charged ions corresponding to (b) glycated ${ }^{89} \mathrm{E}-\mathrm{D}^{98}$ peptide, and (c) glycated ${ }^{136} \mathrm{~F}-\mathrm{K}^{141}$ peptide. 
carboxyl side of the scissible bond [31]. Thus, previous studies demonstrated that $\beta$-LG can be hydrolyzed to a large extent following a trypsin/chymotrypsin digestion $[30,32,33]$. To determine the complex peptide mapping of both digestion mixtures, MALDI-MS and LC-ESI-MS analyses were carried out.

\section{MALDI-MS Analysis}

Figure 2 shows the MALDI-MS profiles of both digested native and glycated $\beta$-LG. Although a large number of ions remained present in both samples, most of those present in the glycated $\beta$-LG were much less abundant. This fact could be attributed to a sum of multiple facts such as the lower ionization power of glycated peptides, the lower susceptibility to digestion for glycated proteins $[14,34]$, or the partial glycation of Lys-containing and/or $N$-terminal peptides. Overall, 58 and 23 peptides covering $97 \%$ and $63 \%$ of the mature $\beta$-LG sequence could be identified by MALDI-MS in the digests of native and glycated samples, respectively (Table 1).

The peptides released at higher intensities from native $\beta$-LG were identified as fragments (by decreasing order of abundance): ${ }^{123} \mathrm{Val}^{-} \mathrm{Phe}^{136}$ ( $\mathrm{m} / \mathrm{z}$ 1647.8), ${ }^{123}$ Val-Lys $^{138}$ ( $m / z$ 1891.9), ${ }^{43} V$ al-Gln ${ }^{59}$ ( $m / z$ 1924.0), and ${ }^{43} V_{\text {Val-Trp }}{ }^{61}(\mathrm{~m} / \mathrm{z} 2238.2)$ (Figure $\left.2 \mathrm{a}\right)$. The peptide ${ }^{123} \mathrm{Val}-$ Lys $^{138}$ was obtained as a result of a combination of chymotryptic and tryptic cleavages occurring at bonds ${ }^{122}$ Leu-Val $^{123}$ and ${ }^{138}$ Lys-Ala $^{139}$, respectively. Then, this peptide was again cleaved by chymotrypsin at the bond ${ }^{136} \mathrm{Phe}-\mathrm{Asp}^{137}$ to eventually release the fragment ${ }^{123}$ Val$\mathrm{Phe}^{136}$. Additionally, the peptides ${ }^{43}$ Val-G $\ln ^{59}$ and ${ }^{43}$ Val-Trp ${ }^{61}$ are probably derived exclusively from the chymotrypsin action by cleaving the bonds ${ }^{42} \mathrm{Tyr}^{-\mathrm{Val}^{43}}$, ${ }^{61} \mathrm{Trp}-\mathrm{Glu}^{62}$, and ${ }^{59} \mathrm{Gln}-\mathrm{Lys}^{60}$. Chicon et al. [35], who also observed the peptides ${ }^{43}$ Val-G $\ln ^{59}$ and ${ }^{43}$ Val-Trp ${ }^{61}$ following chymotrypsin digestion of native $\beta$-LG, indicated that Gln residues can be also cleaved by chymotrypsin, particularly when followed in the sequence by Lys, Arg, Ser, or Thr.

The MALDI spectrum of the digested glycated $\beta-\mathrm{LG}$ was dominated by signals at $m / z$ 1091.5, 1545.6, and 1647.8 , which could correspond to the unglycated peptides ${ }^{133}$ Leu-Lys ${ }^{141},{ }^{149}$ Leu-His ${ }^{161}$ and ${ }^{123}$ Val-Phe ${ }^{136}$, respectively (Figure 2b). On the other hand, taking into consideration that the glycated Lys residues are not cleaved by trypsin $[18,36]$, the tentative disappearance of the assigned peptides ${ }^{1}$ Leu-Lys ${ }^{8},{ }^{20} \mathrm{Tyr}-\mathrm{Arg}{ }^{40,}{ }^{33} \mathrm{Asp}-$ Arg ${ }^{40,}{ }^{41}$ Val-Lys ${ }^{60},{ }^{59}$ Gln-Lys ${ }^{70}={ }^{149}$ Leu-Ile ${ }^{162,}{ }^{60}$ LysLys $^{70}$, ${ }^{62}$ Glu-Lys ${ }^{70,}{ }^{76}$ Thr-Lys ${ }^{83,}{ }^{94}$ Val-Lys ${ }^{100,}{ }^{104}$ Leu$\mathrm{Arg}^{124}$ and ${ }^{142} \mathrm{Ala}-\mathrm{Arg}^{148}$ after glycation, could suggest that the Lys residues located at the positions 8, 60, 70, 83, and 100, and the Arg residues at positions 40, 124, and 148 are occupied by GOS (Table 1). However, the rest of Lys or Arg residues cannot be ruled out as potential glycation sites because many unglycated peptides were still detected, indicating that glycation was substoichiometric and, therefore, it is very plausible to detect the same peptide in its glycated and unglycated form [37]. Finally, nine new ionic species of low abundances were detected at $m / z$ values of $1756.8,1567.6$, 1113.5, 1097.5, 1059.4, 982.3, 976.3, 930.4, and 758.3. These mass values might correspond either to glycated short peptides or to unglycated peptides generated by new enzymatic cleavages as glycation may modify enzyme action [14].

\section{LC-ESI-MS Analysis}

Figure 3 illustrates the resulting total ion current (TIC) chromatogram for glycated and unglycated digested proteins. Due to the complexity of the peptides profile and to the incomplete chromatographic separation between nonglycated and glycated peptides, analogous digestion patterns were apparently obtained for unglycated and glycated $\beta$-LG $[13,19]$. A similar behavior was observed for other proteins such as bovine serum albumin (BSA) [34] or HSA [14, 38]. In good agreement with this, 33 of the 47 unglycated peptides identified in the digest of native $\beta$-LG were also detected in that of glycated $\beta$-LG (Table 2 ). Around $91 \%$ and $77 \%$ of the $\beta$-LG sequence were covered by the peptides identified by LC-ESI-MS in the digests of the native and glycated protein, respectively.

However, some minor differences such as the disappearance of some peaks or the formation of peak shoulders were found between both TIC profiles, suggesting the presence of glycated peptides. Furthermore, the LC-ESI-MS analysis of the digest of glycated $\beta$-LG showed numerous spectra dominated by series of doubly or triply charged ions differing by 81 or $54 \mathrm{u}$, respectively. This indicated that these spectra were characterized by the presence of the same peptide glycated with GOS of different degrees of polymerization, explaining the accumulated difference in one unit of galactose (162 u). As examples, Figures 4 and 5 show the electrospray mass spectra of the peptides ${ }^{43} \mathrm{Val}-$ Gln ${ }^{59}$ and ${ }^{43}$ Val-Trp $^{61}$ either in their unglycated or glycated (with GOS ranging from 2 to 6 units of galactose) form. Table 3 summarizes the 19 peptides glycated with GOS of different degrees of polymerization (from 2 to 7) identified by LC-ESI-MS. Glycated peptides had shorter retention times in the reversedphase column than their unglycated forms (Tables 2 and 3) due to that the incorporation of GOS residues into the peptide chain leads to an increase in peptide hydrophilicity.

Overall, from these results can be inferred that Lys residues located at positions $14,47,75,77,83,91,100$, 135 , and 138, as well as the $\mathrm{NH}_{2}$-terminal Leu residue, are GOS glycation-sites. Morgan et al. [22] and Fenaille et al. [24] observed that Lys residues at 47 and 91 were the first modified sites following dry-state lactosylation of bovine $\beta$-LG, although the rest of Lys residues were also glycated when longer incubation times were carried out. 


\section{LC-ESI-MS/MS Analysis}

LC-ESI-MS/MS analyses were performed to confirm the structure of those peptides which showed the highest relative abundances by MALDI-MS and LC-ESI-MS. Marked differences in the fragmentation behavior between glycated and unglycated peptides were found. Thus, the unglycated peptides produced a MS/MS spectrum in which the typical $y$ - and b-series predominate (data not shown). The 22 unglycated peptides identified by tandem MS were located at the $\mathrm{NH}_{2}$ terminus and at the regions spanning the residues $20-32,40-61,71-100$, and 123-138. Without reduction, no peptides containing cysteine residues were assigned, suggesting that all cysteines in $\beta$-LG could be participating in disulfide bridges.

The tandem mass spectra of the glycated peptides identified by LC-ESI-MS (Table 3) were mainly characterized by the formation of the furylium ion and its subsequent $\mathrm{CHOH}$ loss. Other minor ionic species containing the furylium ring linked to galactose units could be also detected, pointing out the diversity of the fragmentation pattern of peptides glycated with larger size carbohydrates. As an example, Scheme 1 illustrates a possible fragmentation pathway of a peptide glycated with a tetrasaccharide compatible with the main ions detected by MS/MS. Mollé et al. [21] and Jeric et al. [39] described the pathways for the formation of the furylium ion and its $\mathrm{CHOH}$ loss from Amadori rearrangement products involving di- and monosaccharides linked to a peptidic chain, respectively. The data reported in our study demonstrate that these ionic species are also formed following ESI-MS/MS analysis of peptides glycated with carbohydrates of higher molecular weight. Thus, the losses of 1026/1056, 864/894, 702/ $732,540 / 570,378 / 408$, and $216 / 246 \mathrm{u}$ were indicative of the peptide glycation with hepta-, hexa-, penta-, tetra-, tri-, and disaccharides, respectively. Considering the presence of doubly and triply charged glycated peptides, these mass values were also divided by 2 and 3 to scan for constant formal neutral losses. Figure $6 a$ and $b$ show the MS/MS spectra of the peptides ${ }^{83} \mathrm{Lys}^{-\mathrm{Glu}^{89}}$ and ${ }^{89} \mathrm{Glu}$-Asp ${ }^{98}$ glycated with GOS of 4 and 5 hexose units, respectively. Strikingly, MS/MS spectra of two glycated peptides, ${ }^{136} \mathrm{Phe}^{-L y s}{ }^{141}$ (Figure $6 \mathrm{c}$ ) and ${ }^{43}$ ValGlyn $^{59}$ (spectrum not shown), were dominated by singly and doubly charged ions derived exclusively from losses of galactose units (Figure 6c).

\section{Conclusions}

In general terms, a good correlation between the molecular masses obtained for the unglycated peptides by ESI-MS and MALDI-MS was obtained, although peptides with low masses $(<800 \mathrm{u})$ were mainly identified by LC-ESI-MS, whereas those with mass values between 2300 and $3000 \mathrm{u}$ were detected by MALDI-MS. On the contrary, substantial differences between both MS techniques were observed for the detection of the glycated peptides, where LC-ESI-MS showed to be a more effective technique than MALDI-MS.

Further ESI-MS/MS analyses corroborated the LCESI-MS results and also enabled an extensive investigation into the glycated peptides produced by the in vitro gastrointestinal digestion. Thus, the formation of the characteristic furylium ion and its $\mathrm{CHOH}$ loss allowed the detection of a number of peptides glycated with GOS of different degrees of polymerization (from 2 to 7). Consequently, the putative GOS glycation sites were located at the $\mathrm{NH}_{2}$-terminal Leu residue and at the Lys residues $14,47,75,77,83,91,100,135$, and 138 . The structural characterization of the glycated peptides surviving the in vitro gastrointestinal digestion of $\beta$-LG described in this work is important for future studies investigating the effect of these peptides on the gut microbiota.

\section{Acknowledgments}

The authors gratefully acknowledge supported of this work by projects 200670M027, ALIBIRD S-0505/AGR/000153, and ANALYSIC S-505/AGR-0312 financed by the Comunidad de Madrid. The authors thank to Dr. G. Klarenbeek and Dr. J. de Slegte from Borculo Domo for providing them with Vivinal-GOS.

\section{References}

1. Borrelli, R. C.; Visconti, A.; Mennella, C.; Anese, M.; Fogliano, V. Chemical Characterization and Antioxidant Properties of Coffee Melanoidins. J. Agric. Food Chem. 2002, 50, 6527-6533.

2. Xu, Q. P.; Tao, W. Y.; Ao, Z. H. Antioxidant Activity of Vinegar Melanoidins. Food Chem. 2007, 102, 841-849.

3. Brownlee, M.; Vlassara, H.; Cerami, A. Nonenzymatic Glycosylation and the Pathogenesis of Diabetic Complications. Ann. Intern. Med. 1984 101, 527-537.

4. Horie, K.; Miyata, T.; Maeda, K.; Miyata, S.; Sugiyama, S.; Sakai, H.; de Strihou, C. V.; Monnier, V. M.; Witztum, J. L.; Kurokawa, K. Immunohistochemical Colocalization of Glycoxidation Products and Lipid Peroxidation Products in Diabetic Renal Glomerular Lesions-Implication for Glyco-oxidative Stress in the Pathogenesis of Diabetic Nephropathy. J. Clin. Invest. 1997, 100, 2995-3004.

5. Erbersdobler, H. F.; Faist, V. Metabolic Transit of Amadori Products. Nahrung 2001, 45, 177-181.

6. Faist, V.; Erbersdobler, H. F. Metabolic Transit and in Vivo Effects of Melanoidins and Precursor Compounds Deriving from the Maillard Reaction. Ann. Nutr. Metab. 2001, 45, 1-12.

7. Finot, P. A. The Absorption and Metabolism of Modified Amino Acids in Processed Foods. J. AOAC Int. 2005, 88, 894-903.

8. Ames, J. M.; Wynne, A.; Hofmann, A.; Plos, S.; Gibson, G. R. The Effect of a Model Melanoidin Mixture on Fecal Bacterial Populations in Vitro. Br. J. Nutr. 1999, 82, 489-495.

9. Dell'Aquila, C.; Ames, J. M.; Gibson, G. R.; Wynne, A. G. Fermentation of Heated Gluten Systems by Gut Microflora. Eur. Food Res. Technol. 2003, 217, 382-386

10. Tuohy, K. M.; Hinton, D. J. S.; Davies, S. J.; Crabbe, M. J. C.; Gibson, G. R.; Ames, J. M. Metabolism of Maillard Reaction Products by the Human Gut Microbiota-Implications for Health. Mol. Nutr. Food Res. 2006, 50, 847-857.

11. Gibson, G. R.; Roberfroid, M. B. Dietary Modulation of the Human Colonic Microbiota: Introducing the Concept of Prebiotics. J. Nutr. 1995, $125,1401-1412$

12. Rastall, R. A.; Maitin, V. Prebiotics and Synbiotics: Towards the Next Generation. Curr. Opin. Biotechnol. 2002, 13, 490-496.

13. Sanz, M. L.; Corzo-Martínez, M.; Rastall, R. A.; Olano, A.; Moreno, F. J. Characterization and in Vitro Digestibility of Bovine $\beta$-Lactoglobulin Glycated with Galacto-oligosaccharides. J. Agric. Food Chem. 2007, 55, 7916-7925

14. Lapolla, A.; Fedele, D.; Reitano, R.; Arico, N. C.; Seraglia, R.; Traldi, P.; Marotta, E.; Tonani, R. Enzymatic Digestion and Mass Spectrometry in the Study of Advanced Glycation End Products/Peptides. J. Am. Soc. Mass Spectrom. 2004, 15, 496-509.

15. Meltretter, J.; Seeber, S.; Humeny, A.; Becker, C. M.; Pischetsrieder, M. Site-Specific Formation of Maillard, Oxidation, and Condensation Products from Whey Proteins During Reaction with Lactose. J. Agric. Food Chem. 2007, 55, 6096-6103. 
16. Brancia, F. L.; Bereszczak, J. Z.; Lapolla, A.; Fedele, D.; Baccarin, L.; Seraglia, R.; Traldi, P. Comprehensive Analysis of Glycated Human Serum Albumin Tryptic Peptides by Off-Line Liquid Chromatography Followed by MALDI Analysis on a Time-of-Flight/Curved Field Reflectron Tandem Mass Spectrometer. J. Mass Spectrom. 2006, 41, 11791185 .

17. Frolov, A. Hoffmann, P. Hoffmann, R. Fragmentation Behavior of Glycated Peptides Derived from D-Glucose, D-Fructose, and D-Ribose in Tandem Mass Spectrometry. J. Mass Spectrom. 2006, 41, 1459-1469.

18. Morgan, F.; Leonil, J.; Molle, D.; Bouhallab, S. Nonenzymatic Lactosylation of Bovine $\beta$-Lactoglobulin Under Mild Heat Treatment Leads to Structural Heterogeneity of the Glycoforms. Biochem. Biophys. Res. Commun. 1997, 236, 413-417.

19. Leonil, J.; Molle, D.; Fauquant, J.; Maubois, J. L.; Pearce, R. J.; Bouhallab, S. Characterization by Ionization Mass Spectrometry of Lactosyl $\beta$ Lactoglobulin Conjugates Formed During Heat Treatment of Milk and Whey, and Identification of One Lactose-Binding Site. J. Dairy Sci. 1997, $80,2270-2281$

20. Fogliano, V.; Monti, S. M.; Visconti, A.; Randazzo, G.; Facchiano, A. M.; Colonna, G.; Ritieni, A. Identification of a $\beta$-Lactoglobulin Lactosylation site. Biochim. Biophys. Acta 1998, 1388, 295-304.

21. Mollé, D.; Morgan, F.; Bouhallab, S.; Leonil, J. Selective Detection of Lactolated Peptides in Hydrolysates by Liquid Chromatography Electrospray Tandem Mass Spectrometry. Anal. Biochem. 1998, 259, 152-161.

22. Morgan, F.; Bouhallab, S.; Molle, D.; Henry, G.; Maubois, J. L.; Leonil, J. Lactolation of $\beta$-Lactoglobulin Monitored by electrospray Ionization Mass Spectrometry. Int. Dairy J. 1998, 8, 95-98.

23. Fenaille, F.; Morgan, F.; Parisod, V.; Tabet, J. C.; Guy, P. A. Solid-State Glycation of $\beta$-Lactoglobulin Monitored by Electrospray Ionization Mass Spectrometry and Gel Electrophoresis Techniques. Rapid Commun. Mass Spectrom. 2003, 17, 1483-1492.

24. Fenaille, F.; Morgan, F.; Parisod, V.; Tabet, J. C.; Guy, P. A. Solid-State Glycation of $\beta$-Lactoglobulin by Lactose and Galactose: Localization of the Modified Amino Acids Using Mass Spectrometric Techniques. J. Mass Spectrom. 2004, 39, 16-28.

25. Moreno, F. J.; Mellon, F. A.; Wickham, M. S. J.; Bottrill, A. R.; Mills, E. N. C. Stability of the Major Allergen Brazil Nut 2S Albumin (Ber e 1) to Physiologically-Relevant in Vitro Gastrointestinal Digestion. FEBS J. 2005, 272, 341-352.

26. Eigel, W. N.; Butler, J. E.; Ernstrom, C. A.; Farrell, H. M.; Harwalkar, V. R.; Jenness, R.; Whitney, R. M. Nomenclature of Proteins of Cow's Milk, Fifth Revision. I. Dairy Sci. 1984, 67, 1599-1631.

27. Reddy, I. M.; Kella, N. K. D.; Kinsella, J. E. Structural and Conformational Basis of the Resistance of $\beta$-Lactoglobulin to Peptic and Chymotryptic Digestion. J. Agric. Food Chem. 1988, 36, 737-741.
28. Dalgalarrondo, M.; Dufour, E.; Chobert, J.-M.; Bertrand-Harb, C. Haertle, T. Proteolysis of $\beta$-Lactoglobulin and $\beta$-Casein by Pepsin in Ethanolic Media. Int. Dairy J. 1995, 5, 1-14.

29. Astwood, J. D.; Leach, J. N.; Fuchs, R. L. Stability of Food Allergens to Digestion in Vitro. Nat. Biotechnol. 1996, 14, 1269-1273.

30. Peyron, S.; Mouecoucou, J.; Fremont, S.; Sanchez, C.; Gontard, N. Effects of Heat Treatment and Pectin Addition on $\beta$-Lactoglobulin Allergenicity. J. Agric. Food Chem. 2006, 54, 5643-5650.

31. Gauthier, S. F. Pouliot, Y. Functional and Biological Properties of Peptides Obtained by Enzymatic Hydrolysis of Whey Proteins. J. Dairy Sci. 2003, 86, E78-87.

32. Van Willige, R. W. G.; Fitzgerald, R. J.Tryptic and Chymotryptic Hydrolysis of $\beta$-Lactoglobulin-A, $\beta$-Lactoglobulin-B, and $\beta$-Lactoglobulin-AB at Ambient and High-Pressure. Milchwissenschaft 1995, 50, 183-186.

33. Galvao, C. M. A.; Silva, A. F. S.; Custodio, M. F.; Monti, R.; Giordano, R. D. C. Controlled Hydrolysis of Cheese Whey Proteins Using Trypsin and $\alpha$-Chymotrypsin. Appl. Biochem. Biotechnol. 2001, 91-93, 761-776.

34. Lapolla, A.; Fedele, D.; Martano, L.; Arico, N. C.; Garbeglio, M.; Traldi, P.; Seraglia, R.; Favretto, D. Advanced Glycation End Products: A Highly Complex Set of Biologically Relevant Compounds Detected by Mass Spectrometry. J. Mass Spectrom. 2001, 36, 370-378.

35. Chicon, R.; Lopez-Fandino, R.; Quiros, A.; Belloque, J. Changes in Chymotrypsin Hydrolysis of $\beta$-Lactoglobulin A Induced by High Hydrostatic Pressure. J. Agric. Food Chem. 2006, 54, 2333-2341.

36. Henle, T.; Klostermeyer, H. The Reactivity of the Individual ProteinBound Lysine Residues of $\beta$-Casein a1 During the Initial Stages of the Maillard Reaction. In International Dairy Federation Special Issue 9303. Protein and Fat Globule Modifications by Heat Treatment, Homogenization, and Other Technological Means for High Quality Dairy Products; International Dairy Federation: Brussels, Belgium, 1993; p. 183-189.

37. Lapolla, A.; Brancia, F. L.; Bereszczak, J.; Fedele, D.; Baccarin, L.; Seraglia, R.; Traldi, P. Off-Line Liquid Chromatography-MALDI by with Various Matrices and Tandem Mass Spectrometry for Analysis of Glycated Human Serum Albumin Tryptic Peptides. Mol. Nutr. Food Res. 2007, 51, 456-461.

38. Lapolla, A.; Fedele, D.; Senesi, A.; Arico', N. C.; Reitano, R.; Favretto, D.; Seraglia, R.; Astner, H.; Traldi, P. Advanced Glycation Endproducts/ Peptides: A Preliminary Investigation by LC and LC/MS. Farmaco 2002, 57, 845-852.

39. Jeric, I.; Versluis, C.; Horvat, S.; Heck, A. J. R. Tracing Glycoprotein Structures: Electron Ionization Tandem Mass Spectrometric Analysis of Sugar-Peptide Adducts. J. Mass Spectrom. 2002, 37, 803-811. 